\title{
DEXMEDETOMIDINE- A WONDER DRUG IN PATIENTS WITH VON RECKLINGHAUSEN NEUROFIBROMATOSIS DURING SCOLIOSIS CORRECTION SURGERY
}

\author{
Nishtala Madhavi ${ }^{1}$, Bhargavi Sanket ${ }^{2}$
}

${ }^{1}$ Associate Professor, Department of Anaesthesiology, Indira Gandhi Institute of Child Health, Bangalore.

${ }^{2}$ Senior Resident, Department of Anaesthesiology, Indira Gandhi Institute of Child Health, Bangalore.

\begin{tabular}{l}
\hline ABSTRACT \\
BACKGROUND \\
Scoliosis, a major surgery conducted under general anaesthesia causes significant neuroendocrine stress response. Conduct of the \\
wake-up test may further exaggerate the stress response due to the uncomfortable prone position during surgery and also \\
presence of an endotracheal tube in situ during conduct of the test. Dexmedetomidine causes modulation of catecholamine release, \\
which minimises the neuroendocrine and haemodynamic stress response.
\end{tabular}

\section{MATERIALS AND METHODS}

50 cases of NF-1 coming for scoliosis repair were studied over 4 years prospectively for quality of wake-up test, control of blood loss and haemodynamic stability due to administration of Dexmedetomidine infusion. Dexmedetomidine was started intravenously as a bolus $1 \mathrm{ug} / \mathrm{kg}$ over 10 minutes followed by $1 \mathrm{ug} / \mathrm{kg} /$ hour infusion. HR, ECG, $\mathrm{SpO}_{2}$, IABP, temperature and urine output was monitored. Wake-up test: Surgeons requested for wake-up test half an hour in advance. Atracurium infusion was stopped. Isoflurane was stopped 15 mins later. Dexmedetomidine was continued at $0.5 \mu \mathrm{g} / \mathrm{kg} / \mathrm{hr}$.

Study Design- Descriptive Study.

\section{RESULTS}

In our study, we did not see any of these complications and all 50 patients had good quality of wake-up test. The patients were calm due to the hypnotic and anxiolytic actions of dexmedetomidine. They responded to commands equivalent to a Ramsay sedation scale of 2. They were pain free, haemodynamically stable with good spontaneous respiration. Intraoperative period was characterised by haemodynamic stability (Heart rate was maintained between 80 - 120/mins, ABP- 70 / 40 - 100/ 60 mmHg, P-max $20-24 \mathrm{mmHg}$ ). Average blood loss was around $15 \mathrm{~mL} / \mathrm{kg}$ body weight. Major blood loss requiring massive blood transfusion was not seen; 1 unit of packed cells was transfused in each of the 50 cases.

\section{CONCLUSION}

Intraoperative dexmedetomidine use has multiple advantages in NF-1 patients undergoing scoliosis corrective surgery. A randomised controlled study is necessary to statistically evaluate the multiple benefits of dexmedetomidine.

\section{KEYWORDS}

Dexmedetomidine, Fentanyl, Paediatric, Procedural Sedation, Regional Anaesthesia.

HOW TO CITE THIS ARTICLE: Madhavi N, Sanket B. Dexmedetomidine- a wonder drug in patients with Von Recklinghausen neurofibromatosis during scoliosis correction surgery. J. Evolution Med. Dent. Sci. 2017;6(92):6621-6624, DOI: $10.14260 /$ jemds/2017/1435

\section{BACKGROUND}

Von Recklinghausen Neurofibromatosis or Neurofibromatosis 1 (NF-1) is an autosomal dominant neuroectodermal disease. It is characterised by café-au-lait spots, peripheral nerve tumours and soft tissue tumours. Scoliosis is seen as the most common skeletal deformity and is seen in $10 \%-25 \%$ of NF-1 patients. $(1,2,3)$ Neurological damage intraoperatively during scoliosis correction is one of the dreaded complications and wake-up test remains the gold standard test to confirm spinal motor integrity.(4) Scoliosis corrective surgery is associated with increased blood loss intraoperatively.(5) Also plexiform neurofibromas are highly vascular with abnormal friable blood vessels, carrying a

'Financial or Other Competing Interest': None.

Submission 27-10-2017, Peer Review 18-11-2017,

Acceptance 22-11-2017, Published 04-12-2017.

Corresponding Author:

Dr. Madhavi Nishtala,

007 Aishwarya Bliss,

7th Cross, Sarakki Main Road,

JP Nagar, Phase 1, Bangalore.

E-mail:mnishtala@yahoo.com

DOI: $10.14260 /$ jemds $/ 2017 / 1435$ significant risk for bleeding during surgery.(6)

Dexmedetomidine is a selective $\alpha-2$ adrenoreceptor agonist. It is fast becoming a popular anaesthetic adjuvant for sedative, anxiolytic, analgesic and sympatholytic actions. Dexmedetomidine was planned to be used intraoperatively in NF-1 patients coming for scoliosis correction as anaesthetic adjuvant to aid in conduct of the wake-up test for early detection of neurological injury. It was also hypothesised to be advantageous intraoperatively by providing hypotensive anaesthesia, decreasing anaesthetic requirements and to blunt stress response. $(7,8)$

\section{Study Design \\ Descriptive Study.}

\section{MATERIALS AND METHODS}

50 children between the ages of 9 and 16 years diagnosed with NF-1 and posted for scoliosis correction surgery were selected for the study. There were 36 males and 14 females. Mean weight was $36 \mathrm{Kgs}$. Chief complaint was the upper and mid-thoracic deformity, which was increasing progressively. No restriction of activity was seen in 47 patients; 3 patients 
had lower limb muscle weakness and wasting. None had any other comorbidities.

Systemic Examination: All 50 had thoracic scoliosis with a mean curvature of 60 degrees to either left or right. All of them had café-au-lait spots. Crowding of ribs on one side was seen; 36 patients had moderately restrictive pattern on pulmonary function test; 14 patients had normal PFTs. MRI spine revealed a homogeneous enhancing lobulated right paravertebral mass at various levels suspected to be neurofibroma in all patients. Room air saturation was between $95 \%$ and $100 \%$. Complete blood count was within normal limits in all patients. 2D Echo was normal in all.

38 patients were posted for posterior rod insertion; 12 were posted for posterior decompression of dorsal cord with removal of internal fibres of neurofibroma with corrective instrumentation.

\section{Anaesthetic Management}

Informed consent from the guardian and patients were taken. The patients were explained in detail about the procedure, anaesthesia and the conduct of wake-up test intraoperatively. Premedication with Tab. Diazepam $5 \mathrm{mg}$ at night and 6 am the day of surgery was advised.

In the operating room, the patients were connected to routine monitors. Induction of general anaesthesia was obtained with Inj. Thiopentone $5 \mathrm{mg} / \mathrm{kg}$, Morphine $0.1 \mathrm{mg} / \mathrm{kg}$ and Atracurium $0.5 \mathrm{mg} / \mathrm{kg}$. Airway was secured with appropriate size flexometallic tubes. Bilateral air entry was confirmed and connected to circle system on pressure controlled ventilation. Pi was $18 \mathrm{mmHg}$ and respiratory rate 20/ min was set. Tidal volume of $8 \mathrm{~mL} / \mathrm{kg}$ was achieved. Maintenance of anaesthesia was achieved with oxygen 50\% in nitrous oxide, isoflurane $0.2 \%-0.6 \%$ and continuous atracurium infusion $0.5 \mathrm{mg} / \mathrm{kg} / \mathrm{hr}$. Right IJV was catheterised with $5 \mathrm{~F}$ double lumen catheter and left radial artery was cannulated with $22 \mathrm{~g}$ cannula for continuous ABP monitoring and arterial sampling for blood gas analysis. Injection tranexamic acid $10 \mathrm{mg} / \mathrm{kg}$ bolus and $10 \mathrm{mg} / \mathrm{kg}$ infusion was started. Dexmedetomidine was started intravenously as bolus $1 \mathrm{ug} / \mathrm{kg}$ over 10 minutes followed by 1 $\mathrm{ug} / \mathrm{kg} /$ hour infusion. Patients were put in prone position with due precautions.

\section{Monitoring}

Intraoperatively, $\mathrm{HR}, \mathrm{ECG}, \mathrm{SpO}_{2}$, IABP, temperature and urine output was monitored. Heart rate was maintained between 80 - 120/ min, ABP- 70/40 - 100/ 60 mmHg, Pmax- 20 - 24 mmHg. Normocarbia was ensured. Injection morphine 0.05 $\mathrm{mg} / \mathrm{kg}$ was repeated. When the allowable blood loss was exceeded, replacement with packed RBCs was done.

Wake-up Test: Surgeons requested for wake up-test half an hour in advance. Atracurium infusion was stopped. Isoflurane was stopped 15 mins later. Dexmedetomidine was continued at $0.5 \mu \mathrm{g} / \mathrm{kg} / \mathrm{hr}$. Patients were asked to move their hands and feet. Immediately, after limb movement was confirmed, plane of anaesthesia was deepened with Inj. Propofol $20 \mathrm{mg}$ with atracurium $5 \mathrm{mg}$ and isoflurane concentration was increased.

At the end of the procedure, patient was turned supine. Reversal was administered and patients were extubated when fully awake and obeying commands.

\section{RESULTS}

All 50 patients maintained stable haemodynamics. Mean blood loss was around $15 \mathrm{~mL} / \mathrm{kg}$ bodyweight. During wakeup test, all patients had quiet awakening and obeyed commands. Postoperatively, patients were breathing well, calm with good pain relief and shifted to PICU for monitoring. Patient was not extubated in one case, because of extensive and prolonged surgery.

\section{DISCUSSION}

NF-1 patients coming for surgery pose multiple anaesthetic challenges.(9) Coexistence of scoliosis and its corrective surgery further compound the anaesthetic issues. $(10,11)$

Dexmedetomidine is a selective alpha-2 agonist with multiple actions due to the presence of alpha-2 receptors at various sites in the human body. In general, agonism of presynaptic alpha- 2 receptors causes decreased release of norepinephrine. By acting at the locus coeruleus which is the major modulator of vigilance and nociceptive neurotransmission, dexmedetomidine causes sedation, hypnosis, analgesia and anxiolysis with amnesia. Sedation by dexmedetomidine is unique as it resembles normal sleep. It is also associated with wide safety margin with dose as much as 15 times the therapy associated plasma levels not causing respiratory depression. Antinociceptive effect is also produced at the spinal cord level by action at the substantia gelatinosa inhibiting the release of substance $\mathrm{P}$ and glutamate. Action on the central post-synaptic alpha-2 receptors causes sympatholysis with hypotension, bradycardia and decreased stress response to surgery. Each of these actions of dexmedetomidine have been found useful in patients of the present case series.(12,13)

Neurological damage and paralysis are the most feared complication of scoliosis corrective surgery either due to vascular compromise or direct pressure on the neural tissue during bony distraction. Multiple tests have been devised including monitoring of sensory and motor evoked potentials and conducting wake-up tests to give an early warning of neural damage. Evoked potentials are affected by the use of anaesthetic agents including inhalational anaesthetics, intravenous anaesthetics and neuromuscular blockers. Hence, their reliability in confirming an intact spinal cord is questionable. Also only monitoring sensory evoked potentials does not suggest integrity of motor pathways. Hence, combined monitoring of sensory and motor evoked potentials is necessary and hence costly and sophisticated equipment. $(10,11,14)$

Wake-up test has been considered as a simple and most reliable test in predicting spinal cord injury. Wake-up test was first described by Vauzelle, Stagnara et al in 1973. A successful test suggests integrity of spinal motor function. The quality of wake-up test has been described.(10,15) Conduct of the wake-up test has been condemned because patients may have a poor quality of the test with sudden emergence, violent movements causing rod dislocation/ accidental extubation, pain or post-operative recall. 


\begin{tabular}{|c|c|}
\hline Scale & Definition \\
\hline Good & $\begin{array}{c}\text { Quiet awakening, patient obeys orders, } \\
\text { voluntary movement of hands and feet }\end{array}$ \\
\hline Satisfactory & $\begin{array}{c}\text { Sudden awakening, patient seems confused, } \\
\text { spontaneous movement of extremities not } \\
\text { endangering spondylodesis }\end{array}$ \\
\hline Poor & $\begin{array}{c}\text { Dramatic awakening, patient is agitated, } \\
\text { violent trunk movements threatening } \\
\text { stability of the device }\end{array}$ \\
\hline \multicolumn{2}{|c|}{ Definition of Quality of Wake-Up Test(15) } \\
\hline
\end{tabular}

In our case series, we did not see any of these complications and all the patients had good quality of wakeup test. The patients were calm due to the hypnotic and anxiolytic actions of dexmedetomidine. They responded to commands equivalent to a Ramsay sedation scale of 2 . They were pain free, haemodynamically stable with good spontaneous respiration. Ibrahim et al also found dexmedetomidine to be a useful drug for the conduct wakeup test during corrective spine surgery, as it is associated with faster recovery and better post-operative amnesia.(16) Bagatini et al also report dexmedetomidine to be associated with good analgesia and amnesia when used for wake-up test during scoliosis correction.(17) Dexmedetomidine has been investigated to provide cooperative sedation during awake carotid endarterectomy and awake craniotomy requiring intense neurological monitoring and found to beneficial.(18)

Major blood loss of upto $10-30 \mathrm{~mL} / \mathrm{kg}$ remains an important role in anaesthetic concern during scoliosis corrective surgery. Degree of blood loss mainly constituting venous blood depends on the number of vertebrae fused, duration of surgery, use of bone graft, adequate positioning of patient avoiding intra-abdominal pressure and positive pressure ventilation. Blood loss has also been found to be more with posterior approach as compared to anterior approach and all 3 patients in our case series have undergone posterior decompression. Arterial hypertension, which is seen in $6 \%$ of NF-1 patients also potentiate blood loss. Plexiform neurofibromas having abnormal and highly friable blood vessels if present in the neuraxial region can cause major blood loss. Hypotensive anaesthesia has been one of the techniques postulated to decrease the blood loss and requirement of blood transfusion. Sodium nitroprusside and nitroglycerin have been advocated for this purpose. Dexmedetomidine produces vasodilatation by central alpha-2 adrenoreceptor agonism and hypotension, though usually considered as an adverse effect of dexmedetomidine may be beneficial in these patients. $(5,7,10,11)$ Gohary et al(19) recommended the use during scoliosis surgery as a hypotensive agent, which may decrease intraoperative blood loss and requirement of blood transfusion. In our experience, intraoperative period was characterised by haemodynamic stability and blood loss was around 250 - $350 \mathrm{~mL}$. Major blood loss requiring massive blood transfusion was not seen; 1 unit of packed cells was transfused in each of these cases.

The sedative and major antinociceptive action of dexmedetomidine decreases the intraoperative requirements of other anaesthetic agents in balanced anaesthesia practice. The MAC of inhalational anaesthetics and requirement of analgesics including opioids have been found to be reduced, which is advantageous in prolonged duration of surgeries like scoliosis correction. $(7,18)$ In our case series, only single bolus dose of morphine was administered after induction dose.
Isoflurane $<0.6$ vol\% was adequate to maintain stable haemodynamics, though intraoperative awareness was not monitored. A further study is required with BIS monitoring to evaluate occurrence of intraoperative awareness associated with the decreased anaesthetic requirement with dexmedetomidine.

Scoliosis corrective surgery is associated with extensive bony manipulation and severe post-operative pain. Multimodal approach to analgesia is required with opioids as the mainstay drugs. Other than restrictive lung disease seen in association with Kyphoscoliosis, NF-1 patients may also present with pulmonary fibrosis, intrapulmonary neurofibromas leading to compromised lung function and making them increasingly sensitive to respiratory depression with opioid use. Scoliosis correction post-operatively is known to further decrease the total lung capacity and vital capacity by upto $40 \%$ making them prone for post-operative pulmonary complications. Hence, post-operative ventilation with slow weaning and extubation in ICU may become necessary. With use of dexmedetomidine and resultant opioid sparing, there is good analgesia with lack of respiratory depression. Hence, at the end of surgery 47 of 50 patients had an optimal analgesia and good respiratory effort allowing on table extubation and minimal respiratory morbidity. Even in the post-operative period, dexmedetomidine is shown to decrease the analgesic requirement by $50 \%$. This action will also benefit NF-1 patients by decreasing opioid requirement for analgesia and favouring good respiratory dynamics. $(7,9,10,18,20)$

\section{CONCLUSION}

Scoliosis, a major surgery conducted under general anaesthesia causes significant neuroendocrine stress response. Conduct of the wake-up test may further exaggerate the stress response due to the uncomfortable prone position during surgery and also presence of an endotracheal tube in situ during conduct of the test. Dexmedetomidine causes modulation of catecholamine release, which minimises the neuroendocrine and haemodynamic stress response. In the present study, the patients were haemodynamically stable in the intraoperative period with absence of reflex tachycardia and hypertension even during the wake-up test. Though conduct of randomised controlled trial with statistical analysis of haemodynamics and stress hormones surge is warranted.(7,18) Bekker et al demonstrated attenuation of stress response with dexmedetomidine during multilevel spine fusion and faster recovery.(21) Hence, intraoperative dexmedetomidine use has multiple advantages in NF-1 patients undergoing scoliosis corrective surgery. A randomised controlled study is necessary to statistically evaluate the multiple benefits of dexmedetomidine.

\section{REFERENCES}

[1] Hirata D, Nara H, Inaba T, et al. Von Recklinghausen disease in a patient with X-linked agammaglobulinemia. Inter Med 2002;41(11):103943.

[2] Fox CJ, Tomajian S, Kaye AJ, et al. Perioperative management of neurofibromatosis type 1 . Ochsner J 2012;12(2):111-21. 
[3] Ferner RE. Neurofibromatosis 1 and neurofibromatosis 2: the twenty first century perspective. Lancet Neurol 2007;6(4):340-51.

[4] Penney R. Use of dexmedetomidine and ketamine infusions in scoliosis repair surgery with somatosensory and motor evoked potential monitoring: a case report. AANA journal 2010;78(6):446-50.

[5] Modi NH, Suh WS, Hong JY, et al. Intraoperative blood loss during different stages of scoliosis surgery: a prospective study. Scoliosis 2010;5:16.

[6] Parsons CM, Canter RJ, Khatri VP. Surgical management of neurofibromatosis. Surg Oncol Clin N Am 2009;18(1):175-96.

[7] Gertler R, Brown CH, Mitchelle HD, et al. Dexmedetomidine: a novel sedative-analgesic agent. Proc (Bayl Univ Med Cent) 2001;14(1):13-21.

[8] Bagatini A, Volquind D, Rosso A, et al. Dexmedetomidine as adjuvant drug for wake-up test during scoliosis correction surgery: a case report. Rev Bras Anesthesiol 2004;54(2):247-51.

[9] Hirsch NP, Murphy A, Radcliffe JJ. Neurofibromatosis: clinical presentations and anaesthetic implications. BJA 2001;86(4):555-64.

[10] Kulkarni AH, Ambareesha M. Scoliosis and anaesthetic considerations. Indian Journal of Anaesthesia 2007;51(6):486-95.

[11] Gambrall AM. Anesthetic implications for surgical correction of scoliosis. AANA J 2007;75(4):277-85.

[12] Grewal A. Dexmedetomidine: new avenues. J Anaesth Clin Pharmacol 2011;27(3):297-302.

[13] Afonso J, Reis F. Dexmedetomidine: current role in anesthesia intensive care. Rev Bras Anesthesiol 2012;62(1):118-33.
[14] Raw DA, Beattie JK, Hunter JM. Anesthesia for spinal surgery in adult. British Journal of Anesthesia 2003;91(6):886-904.

[15] Imani F, Jafarian A, Hassani V, et al. Propofol-alfentanyl vs propofol-remifentanil for posterior spinal fusion including wake-up test. Br J Anaesth 2006;96(5):5836.

[16] Nasr IA, Qassem AY, Taalab FH, et al. The quality of the wake-up test in patients undergoing spine surgery: a comparison of two different anesthetic techniques. Ain-Shams Journal of Anesthesiology 2013;6(2):12024.

[17] Bagatini A, Volquind D, Rosso A et al. Dexmedetomidine as adjuvant drug for wake-up test during scoliosis correction surgery: Case report. Rev Bras Anestesiol 2004;54(2):247-51.

[18] Gerlach TA, Dasta FJ. Dexmedetomidine: an updated review. Ann pharmacother 2007;41(2):245-50.

[19] El-Gohary MM, Arafa AS. Dexmedetomidine as a hypotensive agent: efficacy and hemodynamically response during spine surgery for idiopathic scoliosis in adolescents. Egyptian Journal Anaesthesia 2010;26(4):305-11.

[20] Sadhasivam S, Boat A, Mahmoud M. Comparison of patient-controlled analgesia with and without dexmedetomidine following spine surgery in children. Journal of Clinical Anesthesia 2009;21(7):493-501.

[21] Bekker A, Haile M, Kline R, et al. The Effect of Intraoperative Infusion of Dexmedetomidine on Quality of Recovery after Major Spinal Surgery. J Neurosurg Anesthesiol 2013;25(1):16-24. 